\title{
The Somatosensory Amplification in Vitiligo and Chronic Urticaria Patients: A Controlled Study
}

\section{Meltem Sukan and Fulya Maner*}

${ }^{1}$ Department of Psychiatry Bakırköy State Teaching and Research Hospital of Psychiatry and Neurological Sciences, Turkey

\section{Introduction}

Vitiligo is a common acquired disorder that has an estimated incidence of $1-4 \%$ [1]. It is inherited either polygenic or autosomal dominant, with incomplete penetrance and variable expression. Approximately in half of the patients vitiligo developed before the age of 20 [2]. It is characterized by a fairly symmetric pattern of circumscribed macules and patches of amelanosis. Vitiligo has a considerable social and psychological effect on patients because of alteration of appearance $[3,4]$. On the other hand chronic urticaria not only affect the appearance but involves physical discomfort and others view skin lesions as stigmatizing $[5,6]$. Chronic urticaria is a skin disorder which is characterized by wheals and itching. The characteristics of wheals are sudden, lightning quick appearance, sudden redness and swelling which almost signify the explosiveness of an emotion-affective reaction, such as resentment, anger and aggressiveness, presence of pruritus with consequent scratching (even compulsive) signifying anger, tension, aggressiveness as well as embarrassment and shame, the sudden disappearance of the reaction. Suffering chronic urticaria have constant personality characteristics: marked hyperemotivity and anxiety, frequent and extreme states of worry, sensitivity, sense of insecurity and little self-confidence [7].

Somatosensory amplification refers to the tendency to experience bodily sensation as intense, noxious, and disturbing. Individuals focus on unpleasant sensations and to consider them as pathological rather than normal $[8,9]$.

Amplification involves three elements: 1. hyper vigilance, or heightened attentional focus on bodily sensation; 2 . a tendency to select out and concentrate on certain relatively weak and infrequent sensations; and 3. the disposition to react to somatic sensations with affect and cognitions that intensify them and make them more alarming, ominous, and disturbing. People amplify normal physiologic sensations as well as the symptoms of serious medical disease. Thus, amplification encompasses a wide range of somatic stimuli and bodily states, and it is not limited to those sensations that are symptomatic of disease. Amplification is both a state and a trait [9].

A variety of bodily sensations can be amplified: 1 . normal physiological sensations such as intestinal peristalsis. 2. benign dysfunctions, dry skin 3. the visceral and somatic concomitants of intense affect, such as the sympathetic arousal accompanying anxiety 4 . the symptoms of serious nonpsychiatric medical disease [8].

Amplification may serve as a pathogenic mechanism in hypochondriasis, for example, or it may be a more nonspecific concomitant of many psychiatric disorders that are characterized by prominent somatic features.

The aim of this study was to assess the somatosensory amplification in vitiligo and chronic urticaria patients and make a comparison with healthy controls.

\section{Method}

The study populations were recruited from dermatology outpatient clinics at four major hospitals in Istanbul, Leprosis Teaching and Research Hospital of Dermatology, Haseki Teaching and Research Hospital, Istanbul University Cerrahpaşa School of Medicine, Şişli Etfal Teaching and Research Hospital, from February 2003 to December 2004. The diagnosis of vitiligo and chronic urticaria were made by dermatologist by inspection and bacterial, fungal infections or allergic reactions were excluded. 50 vitiligo, 50 chronic urticaria patients, aged 16-60 years were compared with age- and sex- matched 50 healthy controls.

After the procedure had been explained, all subjects gave their written informed consent. The sample completed: 1 . The sociodemographical data form. 2. Somatosensory Amplification Scale (SSAS) 3. The Turkish version of the Structured Clinical Interview for DSM-IV Mental Disorders (SCID-I).

SSAS was developed by Barsky et al. in 1990. It is a self-report questionnaire with 10 items which cover a range of uncomfortable bodily sensations, most of which generally do not connote serious disease [9]. For example, two of the items were "hunger contractions" and "various things happening in my body". It assesses the sensitivity of normal somatic and visceral sensations $[10,11]$. Somatosensory amplification refers to the tendency to experience bodily sensation as intense, noxious, and disturbing. Somatosensory amplification represents the pathologic mechanism in hypochondriasis $[8,10,12]$.

SPSS for Windows version 10.0 was used for data processing and analysis. ANOVA and Tukey HSD was used to compare three groups for quantitatives variables Qualitative features among the groups were compared by $\chi^{2}$ test and Fisher-Exact test.

\section{Results}

$48 \%$ of the vitiligo group are females, $52 \%$ are males; $68 \%$ of the chronic urticaria group are females, $32 \%$ are males; $50 \%$ of the control group are females. The age range of the sample is 16-60. The mean age of vitiligo group is $35.82 \pm 12.56$, chronic urticaria group is $38.66 \pm$ 10.6 , control group is $35.98 \pm 12.49 .50 \%$ are males. $58 \%$ of vitiligo, $70 \%$ of chronic urticaria, $68 \%$ of control group are married. There is no statistically significant difference about age, gender, education and marital status among the groups $(\mathrm{p}>0.05)$. The sociodemographical features of the three groups are presented in Tables 1 and 2.

The rates of dysthymic disorder and generalized anxiety disorder

*Corresponding author: Fulya Maner, Department of Psychiatry Bakırköy State Teaching and Research Hospital of Psychiatry and Neurological Sciences, Turkey, Tel: 905322414102; E-mail: fmaner@ttmail.com

Received December 20, 2014; Accepted April 06, 2015; Published April 08, 2015

Citation: Sukan M, Maner F (2015) The Somatosensory Amplification in Vitiligo and Chronic Urticaria Patients: A Controlled Study. J Neurol Disord 3: 227. doi: 10.4172/2329-6895.1000227

Copyright: ( $) 2015$ Sukan M, et al. This is an open-access article distributed under the terms of the Creative Commons Attribution License, which permits unrestricted use, distribution, and reproduction in any medium, provided the original author and source are credited. 
Citation: Sukan M, Maner F (2015) The Somatosensory Amplification in Vitiligo and Chronic Urticaria Patients: A Controlled Study. J Neurol Disord 3: 227. doi: 10.4172/2329-6895.1000227

Page 2 of 2

\begin{tabular}{|l|l|l|l|l|l|l|l|}
\hline & vitiligo & \multicolumn{3}{l|}{ chronic urticaria } & control & \\
\hline & mean & Sd & mean & Sd & mean & Sd & $p$ \\
\hline Age & 35,82 & 12,56 & 38,66 & 10,61 & 35,98 & 12,49 & 0,411 \\
\hline \multicolumn{7}{|c|}{ Table 1: The mean age of the sample. }
\end{tabular}

\begin{tabular}{|c|c|c|c|c|c|c|c|c|}
\hline & \multicolumn{2}{|c|}{ vitiligo } & \multicolumn{2}{|c|}{ chronic urticaria } & \multicolumn{2}{|c|}{ control } & \multirow[b]{2}{*}{$x^{2}$} & \multirow[b]{2}{*}{ p } \\
\hline & $n$ & $\%$ & $n$ & $\%$ & $n$ & $\%$ & & \\
\hline \multicolumn{9}{|l|}{ Gender } \\
\hline Female & 24 & 48,0 & 34 & 68,0 & 25 & 50,0 & & \\
\hline Male & 26 & 52,0 & 16 & 32,0 & 25 & 50,0 & 4,90 & 0,066 \\
\hline \multicolumn{9}{|l|}{ Marital } \\
\hline Married & 29 & 58,0 & 35 & 70,0 & 34 & 68,0 & & \\
\hline Single-divorced & 21 & 42,0 & 15 & 30,0 & 16 & 32,0 & 1,82 & 0,402 \\
\hline \multicolumn{9}{|l|}{ Education } \\
\hline Elementary & 30 & 60,0 & 35 & 70,0 & 30 & 60,0 & & \\
\hline High School & 11 & 22,0 & 7 & 14,0 & 12 & 24,0 & & \\
\hline University & 9 & 18,0 & 8 & 16,0 & 8 & 16,0 & 2,00 & 0,735 \\
\hline
\end{tabular}

Table 2: Gender, marital status and education of the sample.

were found higher in chronic urticaria group than vitiligo group $(\mathrm{p}<0.05)$ (Table 3$)$. The differences in the rates of other SCID-I diagnoses between the two groups were unsignificant $(p>0.05)$.

The total scores of SSAS were higher in vitiligo and chronic urticaria group than control group $(\mathrm{p}<0.001)$ (Table 4$)$.

\section{Discussion}

In our study we found that the somatosensory amplification and the rates of dysthymic disorder and generalized anxiety disorder higher in the vitiligo and chronic urticaria group than control group. The concept of somatosensory amplification is new and only recently a few studies have been done about this issue.

Symptoms are intensified when they are attributed to a serious disease rather than to more benign causes. Stigmatization and disfigurement in vitiligo and chronic urticaria can cause anxiety and this anxiety may increase their somatosensory amplification. Anxiety lowers the tolerance and threshold for a variety of unpleasant sensations and symptoms, including pain [13]. Chronic pain patients were found to amplify their somatic sensations more than healthy controls, and they also had more difficulty in distinguishing them from bodily sensations of emotion [12].

The concept of somatic amplification is useful in understanding functional somatic symptoms, such as those seen in the somatoform disorders and in masked or somatized depression. Amplification may be a pathogenic mechanism in certain specific amplification disorders such as fibromyalgia and irritable bowel syndrome [9].

Some individuals are generally more sensitive to bodily sensation than others. As a trait, it could be learned in childhood through upbringing and early formative experiences. Situational context furnishes clues that are used to infer the meaning and to decide on the significance of a bodily symptom, thereby influencing how intense and how noxious the symptom seems. Some symptoms, such as itching, have been noted to have an infectious quality; once the symptoms are manifested by one member of a group, others soon experience them as well [8].

\begin{tabular}{|c|c|c|c|c|c|c|}
\hline \multirow[t]{2}{*}{ SCID-I } & \multicolumn{2}{|c|}{ vitiligo } & \multicolumn{2}{|c|}{ chronic urticaria } & \multirow[b]{2}{*}{$x^{2}$} & \multirow[b]{2}{*}{$\mathrm{p}$} \\
\hline & $n$ & $\%$ & $\mathrm{n}$ & $\%$ & & \\
\hline \multicolumn{7}{|c|}{ Dysthymic disorder } \\
\hline yes & 37 & 74,0 & 27 & 54,0 & & \\
\hline no & 13 & 26,0 & 23 & 46,0 & 4,34 & $0,037^{*}$ \\
\hline \multicolumn{7}{|c|}{ Generalized anxiety dis } \\
\hline yes & 47 & 94,0 & 35 & 70,0 & & \\
\hline no & 3 & 6,0 & 15 & 30,0 & & $0,003^{* *}$ \\
\hline
\end{tabular}

Table 3: Distribution of significant SCID-I diagnoses of the patient groups.

\begin{tabular}{|r|l|l|l|l|l|l|l|}
\hline & \multicolumn{3}{|l|}{ vitiligo } & \multicolumn{3}{l|}{ chronic urticaria } & \multicolumn{2}{l|}{ control } & \\
\hline & mean & Sd & mean & Sd & mean & Sd & $p$ \\
\hline SSAS & 31,26 & 6,77 & 31,78 & 7,03 & 17,78 & 9,21 & $0,000^{* * *}$ \\
\hline
\end{tabular}

Table 4: Comparison of somatosensory amplification of the sample.

\section{Conclusion}

The vitiligo and chronic urticaria patients were found to amplify their bodily sensations and feel more anxious and depressive. The cooperation between dermatologists and psychiatrists seems necessary to improve the treatment outcome in these skin disorders.

\section{References}

1. Grunnett I, Howitz J, Reymann F, Schwartz M (1970) Vitiligo and pernicious anemia. Arch Dermatol 101: 82-85.

2. Hafez M, Sharaf L, Abd El-Nabi SM (1983) The genetics of vitiligo. Acta Derm Venereol (Stoch) 63: 249-251.

3. Porter J, Beuf AH, Nordlund JJ, Lerner AB (1979) Psychological reaction to chronic skin disorders: a study of patients with vitiligo. Gen Hosp Psychiatry 1: 73-77.

4. Porter J, Beuf A, Nordlund J, Lerner A (1978) Personal responses of patients to vitiligo: The importance of patient-physician interaction. Arch Dermatol 114: 1384-1385.

5. Nadelson T (1984) A person's boundaries: A meaning of skin disease. Cutis 21: $90-94$.

6. Porter JR, Beuf AH, Lerner A, Nordlund J (1986) Psychosocial effect of vitiligo: a comparison of vitiligo patients with "normal" control subjects, with psoriasis patients, and with patients with other pigmentary disorders. J Am Acad Dermatol 15: 220-224.

7. Panconesi E, Hautmann G (1996) Psychophysiology of stress in dermatology. The psychobiologic pattern of psychosomatics. Dermatologic Clinics 14: 399421

8. Barsky AJ (1992) Amplification, somatization, and the somatoform disorders Psychosomatics 33: 28-34

9. Barsky AJ, Goodson JD, Lane RS, Cleary PD (1988) The amplification of somatic symptoms. Psychosomatic Medicine 50: 510-519.

10. Barsky AJ, Wyshak G, Klerman GL (1990) The somatosensory amplification scale and its relationship to hypochondriasis. J Psychiatr Res 24: 323-334.

11. Speckens AE, Spinhoven P, Sloekers PP, Bolk JH, van Hemert AM (1996) A validation study of the Whitely Index, the Illness Attitude Scales, and the Somatosensory Amplification Scale in general medical and general practice patients. J Psychosom Res 40: 95-104.

12. Ak I, Sayar K, Yöntem T (2004) Alexithymia, somatosensory amplification and counter-dependency in patients with chronic pain. The Pain Clinic 16: 43-51.

13. Sternbach RA (1978) Psychological dimensions and perceptual analyses, including pathologies of pain. In Carterett ED, Friedman MD Handbook of Perception. Academic, New York. 